\section{Medicina Baseadaem Euidencias \\ QUAIS OS FATORES DE RISCO PARA HÉRNIA INGUINAL EM ADULTO?}

P: Pacientes adultos do sexo masculino

I : Presença do fator de risco

C: Ausência do fator de risco

O: Hérnia inguinal primária

Dentre as hérnias, as inguinais são as mais freqüentes na prática clínica, acometendo preferencialmente o sexo masculino. Podem ser divididas em direta e indireta, sendo a primeira mais comum. Acredita-se que alguns fatores ambientais façam parte do desenvolvimento da hérnia direta, como o tabagismo, a idade avançada, desnutrição e a área de ativida de ocupacional.

Com objetivo de avaliar os fatores de risco para hérnia inguinal na população geral, e dando continuidade à edição anterior "À Beira do Leito, Medicina Baseada em Evidências", a qual avaliou estudos de caso-controle, realizamos uma revisão sistemática de estudos coorte, na base Medline, através da estratégia: "Hernia, Inguinal"[Mesh] AND ("Occupational Diseases"[Mesh] OR "Work"[Mesh] OR "Risk Factors"[Mesh]). Foram recuperados 275 artigos, analisados individualmente pelo título e resumo.

$\mathrm{Na}$ análise dos resulta dos foram incluídos os estudos coorte de língua portuguesa, inglesa ou espanhola, relacionados à dúvida clínica (PICO), e que obtiveram escore na escala Newcastle-Ottawa' superior a seis. Foram selecionados dois estudos coorte:

O seguimento de 14.407 homens, de 20 a 74 anos, por I I anos permitiu analisar os fatores idade, raça, peso, IMC, história de hérnia hiatal e tabagismo. Os resultados demonstraram a umento do risco absoluto (ARA) de hérnia inguinal em pacientes com 40 a 59 anos de 3,2\% (NNT 3I) e em pacientes com história de hérnia hiatal de 7,7\% (NNT 13). Mostraram-se fatores de proteção com redução do risco absoluto (RRA): pacientes da raça negra, 4,5\% (NNT 22), peso maior ou igual a 82,3kg, 3,0\% (NNT33) e IMC maior ou igual a trinta, 4, I \% (NNT 24). Nessa amostra, o tabagismo não se revelou como fator de risco para hérnia inguinal2.

Com relação às áreas de atividade ocupacional consideradas de risco para hérnia, foram investiga dos 51 . 246.000 pacientes. Em uma prevalência de seis casos de hérnia inguinal para cada 10.000 trabalhadores dessa população, calculamos o risco absoluto (RA) e a redução (RRA), ou a umento do risco (ARA), e o número necessário a tratar para um benefício (NNT) ou o número necessário a tratar para um dano $(\mathrm{NNH})$, de cada uma dessas áreas de atividade, expressos para 10.000 pacientes:
Temos ARA nas atividades de:

- Limpadores de equipamentos (máquinas ou aparelhos de todos os tipos desde telefones até computadores e copiadoras): 9 (NNH I. I I I)

- Operadores de máquina e encarregados: 6,9 (NNH 1.449)

- Fabricantes, montadores e artesãos: 6,3 (NNH I.587)

- Mecânicos e reparadores: 4,4 (NNH 2.272)

- Trabalho com transporte e locomoção de materiais: 2,7 (NNH 3.703)

- Trabalho em construtoras: 2,3 (NNH 4.347)

E RRA nas áreas de:

- Serviço de suporte técnico (ajuda ou conserto): 2,5 (NNT 4.000)

- Serviços de proteção (serviços sociais): 3,2 (NNT 3. 125)

- Vendedores: 3,5 (NNT 2.857)

- Profissionais especializados: 4,8 (NNT 2.083)

- Executivo, administrador e ocupações especializadas: 5,2 (NNT 1.923)

Na publicação anterior (RAMB 2/2008), baseada em estudos caso-controle, o tabagismo foi considera do como fator de risco para hérnia inguinal (NNH I5), entretanto, desenho de estudo de maior força de evidência (coorte) não confirmou esse achado, o que deve prevalecer como conclusão da revisão.

Percebemos ainda que, apesar do aumento e redução de risco ocorridos nas diversas atividades profissionais, a magnitude do impacto desses fatores no paciente individual, com atividade laborativa nesses ramos, é mínima e muito menor (centenas vezes menor) do que aquela encontrada, de forma isolada, em fatores como idade, raça, peso, IMC e hérnia hiatal.

Entretanto, o risco combinado de um paciente mecânico (ARA: 4,4\% 400 ), com idade entre 40 e 49 anos (ARA: 3,2\%), ter hérnia inguinal, quando a probabilidade pré-teste (prevalência) é de $6,0 \%$, será próximo a zero, reforçando o conceito de que devemos sempre estimar o risco individual de cada paciente, levando em consideração todos os fatores possíveis.

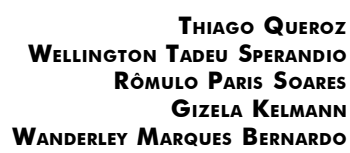

Referências

I. Newcastle: Ottawa Quality Assessment Scale. Available from: http://www.ohri.ca/programs/clinical_epidemiology/nosgen.pdf.

2. Ruhl CE, Everhart JE. Risk factors for inguinal hernia among adults in the US population. Am J Epidemiol. 2007; | 65: | | 54-6 |.

3. Kang SK, Burnett CA, Freund E, Sestito J. Hernia: is it a work-related condition? Am J Ind Med. 1999;36:638-44. 